\title{
Investigating Airplane Crash Data with Watson Analytics and Cognos Analytics
}

\author{
TAIYO MIYAMOTO \\ Concordia International School \\ Hanoi, Vietnam \\ hello.taiyo2@gmail.com
}

\author{
NEIL WHITEHEAD \\ Concordia International School \\ Hanoi, Vietnam \\ whiteheadneila@gmail.com
}

\author{
EMANUEL SANTOS \\ Concordia International School \\ Hanoi, Vietnam \\ emanuel.santos@concordiahanoi.org
}

\begin{abstract}
Over the last century, the world has seen a number of airplane crashes both in the sky and on the ground. The development of technology aims to decrease technological difficulties and human errors. However, fatalities and aircraft damages caused by crashes do not cease to exist.Investigating Airplane Crash Data with Watson Analytics and Cognos Analytics is a big data project that involves discovering and examining airplane crash patterns using IBM's Watson Analytics and Cognos Analytics. This project aims to: (1) find some factors that contribute to crashes, (2) analyze patterns of the data collected from all over the world in the past decades, and (3) find replicable solutions for both aviation industry and customers. This paper looks for correlations between crashes and different variables and predicts when crashes are most likely to happen in a year.The analysis of over 73,000 data points, collected from a subsidiary of Google LLC Kaggle, displays a decrease in the number of airplane crashes and fatalities over the years, an increase in the number of passengers, predictive values for the future years, correlations between different variables, and strong correlations between the occurrence of crashes and the following time variable: yearly, monthly, and daily.The results found in this project will benefit the ongoing investigations into this important topic. Understanding what factors cause airplane crashes helps aviation industries make continuous improvement in flight safety, and help raise customer confidence with the use of statistical evidence.
\end{abstract}

\section{CCS CONCEPTS}

- Information Systems $\rightarrow$ Data management systems; Database design and models; Graph-based database models; • Applied Computing $\rightarrow$ Computer forensics.

\section{KEYWORDS}

Big Data, Watson Analytics, Cognos Analytics, Airplane Crashes, Fatalities, People on Board, Engines, Phase of Flight, Weather, Location, Operator, Yearly Trend, Monthly Trend, Major Accidents, Minor Accidents

Permission to make digital or hard copies of all or part of this work for personal or classroom use is granted without fee provided that copies are not made or distributed for profit or commercial advantage and that copies bear this notice and the full citation on the first page. Copyrights for components of this work owned by others than ACM must be honored. Abstracting with credit is permitted. To copy otherwise, or republish, to post on servers or to redistribute to lists, requires prior specific permission and/or a fee. Request permissions from permissions@acm.org.

ICCBD '20, August 05-07, 2020, Taichung, Taiwan

(C) 2020 Association for Computing Machinery.

ACM ISBN 978-1-4503-8786-6/20/08 . \$ \$15.00

https://doi.org/10.1145/3418688.3418689
ACM Reference Format:

TAIYO MIYAMOTO, NEIL WHITEHEAD, and EMANUEL SANTOS. 2020. Investigating Airplane Crash Data with Watson Analytics and Cognos Analytics. In 2020 the 3rd International Conference on Computing and Big Data (ICCBD '20), August 05-07, 2020, Taichung, Taiwan. ACM, New York, NY, USA, 6 pages. https://doi.org/10.1145/3418688.3418689

\section{INTRODUCTION}

Recently, a well-known athlete, Kobe Bryant, passed away in a helicopter crash along with his daughter and their friends. This tragic event reminded the whole world of the risks of flying.

Airplanes, the most efficient form of modern transportation, make the world a small place by quickly delivering people and cargo from one place to another. As more and more people use airplanes as a means of transportation, the number of passengers and flight routes have expanded in recent years [2]. The scale of airplane crashes varies according to the type of airplane involved, ranging from small-scale cargo planes that only involve a few pilots to large-scale passenger jets that involve hundreds of people.

The number of airplane crashes has decreased over the last few decades; 104 crashes with 2,937 fatalities in 1972 declined to 16 crashes with 838 fatalities in 2018 . However, 838 fatalities is still a great number that we cannot overlook. In fact, on 08 January 2020 , a commercial airplane, the Boeing 737-800 operated by Ukraine International Airlines, was shot down shortly after takeoff from Tehran Imam Khomeini International Airport. All 176 passengers and crew died. Three days later, it was confirmed that the Islamic Revolutionary Guard Corps had shot down the aircraft, having mistakenly identified it as a cruise missile [8]. Even political tension between countries can be a factor of airplane crashes and deaths of innocent people. Hence, despite the decrease in the number of airplane crashes, the risk of crashes that result in casualties cannot be overlooked.

Airplane crashes negatively impact the financial performance of airlines. In fact, airlines experience a significant stock price drop of $2.17 \%$ on the day an airplane crashes, and the price decline remains significant for at least two days after the event [10]. This negative financial impact on airlines also affects national economies and the overall aviation industry. Taking these impacts into consideration, this project aims to discover and analyze correlations for airplane crashes, raise awareness of flight safety, and better understand its problems and progress.

\section{DATA COLLECTION}

\subsection{Collecting Data}

Approximately, 73,000 data points were collected from two different datasets provided by an online community of data scientists and 
machine learning practitioners, Kaggle. One dataset that collects major accidents data-more specifically commercial airplane and military aircraft crashes-has 5,514 data points from 17 September 1908 to 06 November 2018 [1],[5], while the other dataset that collects minor accidents data has 67,640 data points from 01 January 1987 to 31 December 2019 [9].

By examining and comparing two different types of datasets with rich information, this paper investigates a variety of possible factors that influence airplane accidents as well as exploring trends, patterns and correlations in airplane crashes. This information can be used to better predict the occurrence of airplane crashes which can help lead to their prevention.

Moreover, in order to deeply analyze the data, both the old and the updated versions of the datasets were used in this project. This project was done cautiously with the reliability and accuracy of the datasets.

\subsection{Structuring Data}

In addition to Watson Analytics and Cognos Analytics, Google Spreadsheet was used to further clean the datasets and organize data points by removing unnecessary columns and rows; adding old data points to an updated dataset; filling blank cells with correct data; simplifying decimal numbers; and splitting dates into three columns - year, month, and day.

Two spreadsheets were used for the two different datasets. Both spreadsheets, combining old and new datasets, were structured according to different categories. Each category is divided into individual columns.

In the process of cleaning the data, some incorrect or unrecorded cells were replaced with correct data. For example, cells recorded as 'NULL' in the old dataset were replaced with correct numbers from the updated dataset. Moreover, columns that had mainly blank cells were removed so as to examine data with precision.

\subsection{Assessments and Measures}

Besides the main variables such as date and number of passengers and fatalities, this project takes other variables into account, including location, summary, operator, phase of flight, number of engines, engine type, aircraft damage, injury severity, and purpose of flight.

\section{ANALYSIS PROCESS}

\subsection{Using Watson and Cognos Analytics}

IBM Watson Analytics, a data analysis tool, was used to create graphs based on the data and analyze correlations using different variables. In addition, IBM Cognos Analytics was used to further analyze the correlations using various types of visualizations.

3.1.1 Data. After cleaning the datasets using Google Spreadsheet, the datasets were then uploaded on the "Data" tab in Watson Analytics and refined.

3.1.2 Discover. In the "Discovery" tab, some interesting patterns and insights were discovered using Watson's cognitive skills to find patterns and ability to interpret and process language and create visualizations.

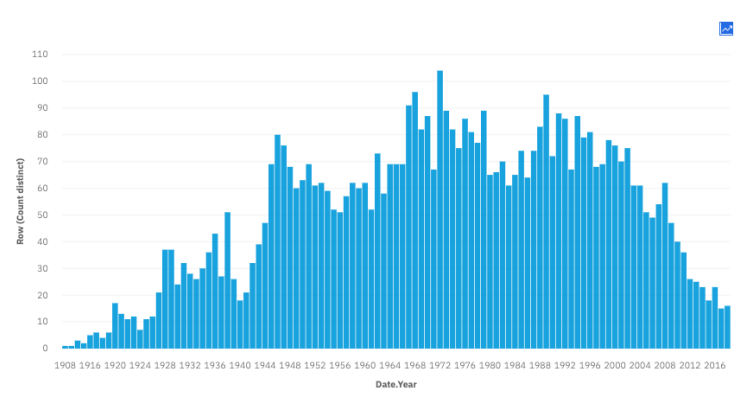

Figure 1: Yearly Trend of Airplane Crashes

3.1.3 Display. In the "Display" tab, the observed patterns from "Discovery" were displayed by more specific visualizations and better organized in a dashboard.

\subsection{Analyzing Two Different Datasets}

In order to find meaningful correlations, two different datasets were used. One has the records of major accidents in the past 110 years with fewer data points and fewer variables. The other has the records of minor accidents in the past 32 years with more data points and more variables. These datasets were respectively classified as major and minor accidents based on the number of fatalities per crash, the scale of damage, the number of engines, and the purpose of flight.

Instead of combining two different datasets, this project keeps them separate in two different categories: major and minor accidents. This step helps prevent confusion during analysis and understand different problems for each category.

\section{FINDINGS - MAJOR ACCIDENTS}

\subsection{Yearly Trend}

Figure 1 shows a gradual increase in the number of crashes from 1908 to 1972 and a dramatic decrease in recent years. The year 1972 was the deadliest year with the highest number of crashes. The crash of the Russian Airlines Aeroflot resulted in the death of all 174 people on board, being the largest crash of that year. In 1972, 104 crashes and 2,937 fatalities were recorded, the worst year on record for the airline industry. A significant improvement in flight safety helped the number of crashes drop by 85\% from 1972 to 2018 .

Furthermore, by calculating linear regression based on this pattern, predictive values can be obtained. According to the formula, the number of crashes could drop down to 25.8 in 2024; 17.8 in 2030; and 9.86 in 2036.

\subsection{Average Number of People on Board and the Total Number of Fatalities}

Figure 2 shows an increase in the average number of people on board, which implies that the number of passengers in general has increased over the years.

The year 1972 had the most number of airplane crashes of all time and became the deadliest year for air travel. Despite the overall decrease in the number of fatalities, the most recent year 2018 had 838 fatalities, which was almost four times more than that of the 


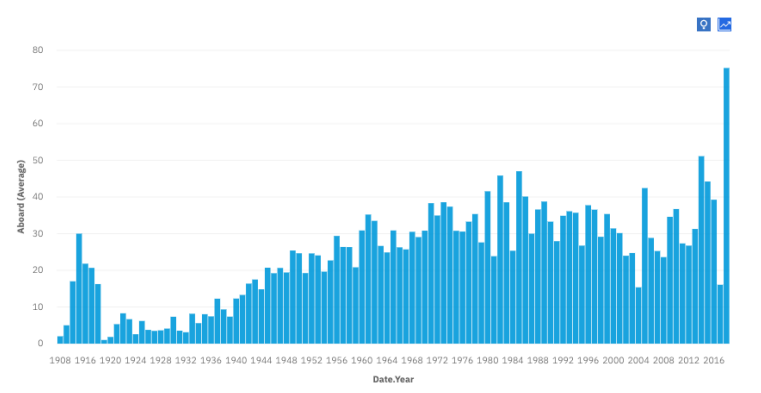

Figure 2: Yearly Trend of the Average Number of People on Board

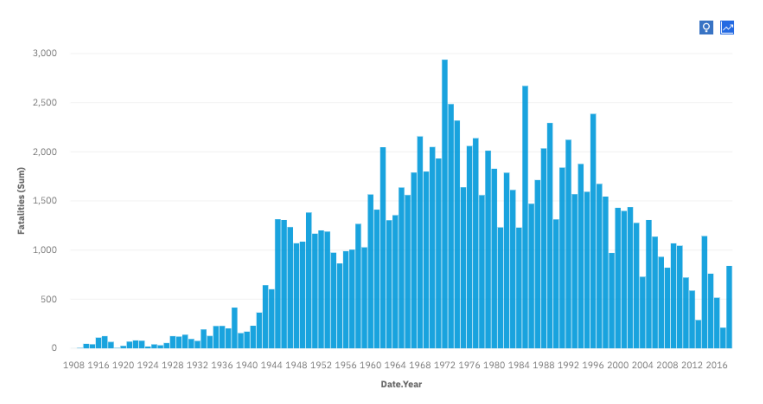

Figure 3: Yearly Trend of the Total Number of Fatalities

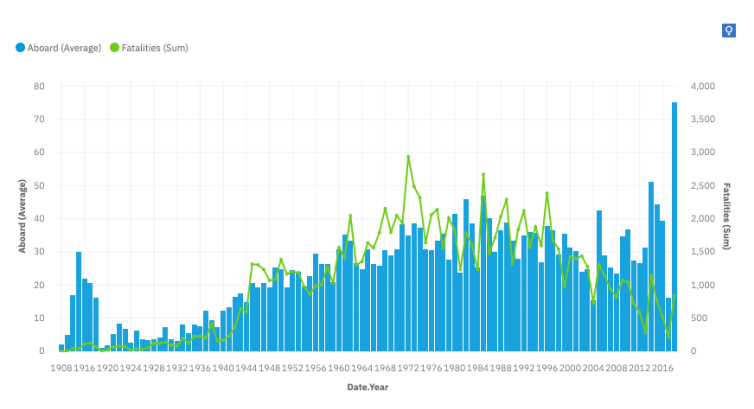

Figure 4: Comparison Between the Average Number of People on Board and the Total Number of Fatalities

previous year 2017 (see Figure 3). The year 2017 was the safest year in the history of commercial airlines [6].

Figure 4 compares Figure 2 and Figure 3. While the average number of people on board has increased, the number of fatalities has decreased over the years, which augurs hopeful results for future years.

In addition, a comparison between the total number of people on board and the total number of fatalities shows that when an airplane crashes, on average there is a $73 \%$ fatality rate among the passengers and crew of that aircraft.

\subsection{Monthly Trend}

Figure 5 shows that there is no definite pattern in the monthly trend, but the number of crashes tends to be a little higher during winter

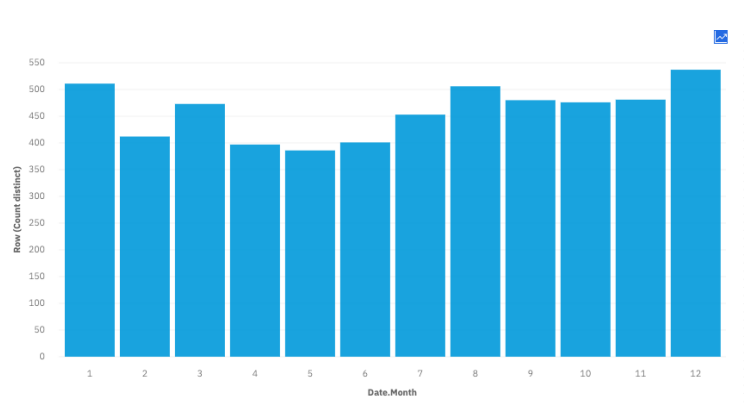

Figure 5: Monthly Trend of Airplane Crashes

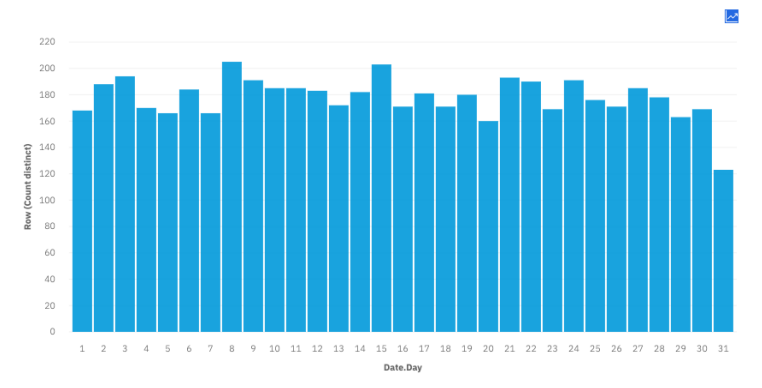

Figure 6: Daily Trend of Airplane Crashes

seasons. According to the National Transportation Safety Board (NTSB), ice is one of the aircraft's greatest threats [11]. This information helps to correlate the cold weather during winter seasons with the high number of crashes seen on the graph.

\subsection{Daily Trend}

Figure 6 shows no unique changes in the daily trend of airplane crashes. There is a dramatic shift in the value on 31st because some months do not have 31 days.

\subsection{Summary}

The dataset also provides brief descriptions of how each crash happened. For example, for the crash on 02 December 1977 by Balkan Bulgarian Airlines that caused 59 fatalities, the summary explains, "After not being able to land at the scheduled airport due to fog, the crew could not find the alternate airport, ran out of fuel and crashed." Some of the most frequent words in the synopsis are 'engine', 'landing', 'take-off', 'fog', and 'rain', which implies that there are higher risks of crashes when engines fail or while taking off or landing in bad weather conditions. Without engines or visual cues, it is difficult for pilots to fly safely. In addition, 'mountain' is another frequent word which implies that many planes crashed into mountains.

\subsection{Location}

Figure 7 shows where airplane crashes occurred over the past 110 years. High crash occurrence regions are colored with dark blue colors. The map indicates that countries that have large military forces such as the United States, Russia, and China have had more 


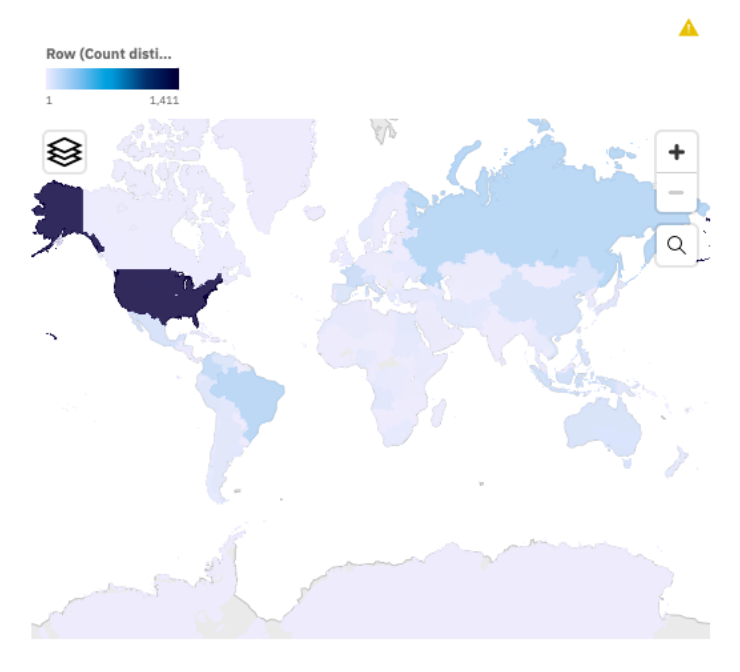

Figure 7: Map of Airplane Crashes

crashes than other countries. Also, Brazil, Columbia and France have high occurrences of crashes.

\subsection{Operator}

Figure 8 shows that among commercial airlines, Russian Airlines, Aeroflot has a record as the airline with the most crashes, 179, followed by 70 crashes from Air France. Today, Aeroflot, $61 \%$ stateowned and one of the largest air carriers in the world, presents a good example of rapid innovative development. Their innovation program aims at increasing safety [4]. As a result, Aeroflot has significantly improved their flight safety in the past few years. One hundred seventy-nine previous crashes, however, are hard to ignore. One of the reasons why Aeroflot has the highest frequency of crashes was the collapse of the country's aircraft manufacturing industry, which caused the Russian airlines to rely on the old aircraft that they had been using for decades [7]. Furthermore, out of all 5,513 crashes, 836 of them were military aircraft crashes.

\section{FINDINGS - MINOR ACCIDENTS}

\subsection{Yearly Trend}

Figure 9 shows that the number of minor crashes has significantly decreased over the last 30 years. A linear regression formula shows that the number of crashes could drop down to 1,000 by the year 2030 .

\subsection{Phase of Flight}

Figure 10 shows phases of flight in which airplane crashes are likely to happen. The two highest peaks are 'Landing' and 'Takeoff'. Although 'Cruise' is the third highest peak, the 'Maneuvering' and 'Approach' phases show that accidents are more likely to happen when planes descend into lower altitudes rather than climb.

*'no value' on the graph means that information was not available.

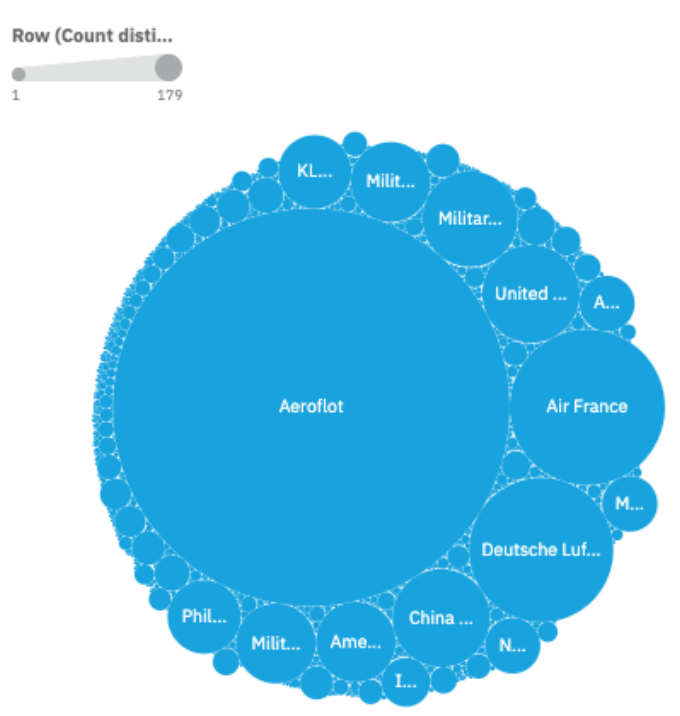

Figure 8: Operators of Aircraft

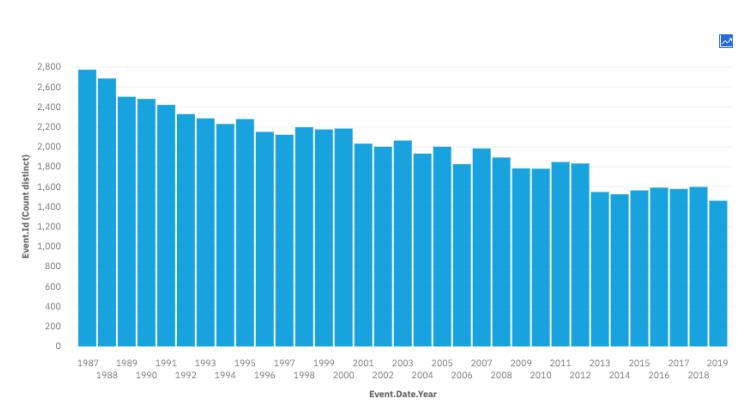

Figure 9: Yearly Trend of Minor Crashes

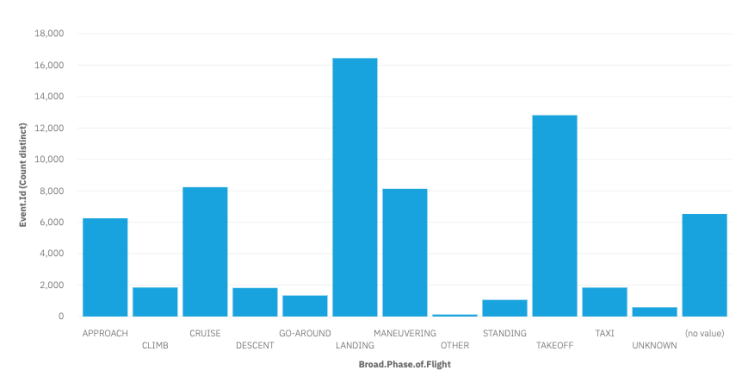

Figure 10: Phase of Flight When Airplane Crashes Occurred

\subsection{Number of Engines}

Figure 11 shows that the majority of aircraft that had minor crashes were single-engined, small sized planes.

*'no value' on the graph means that information was not available. 


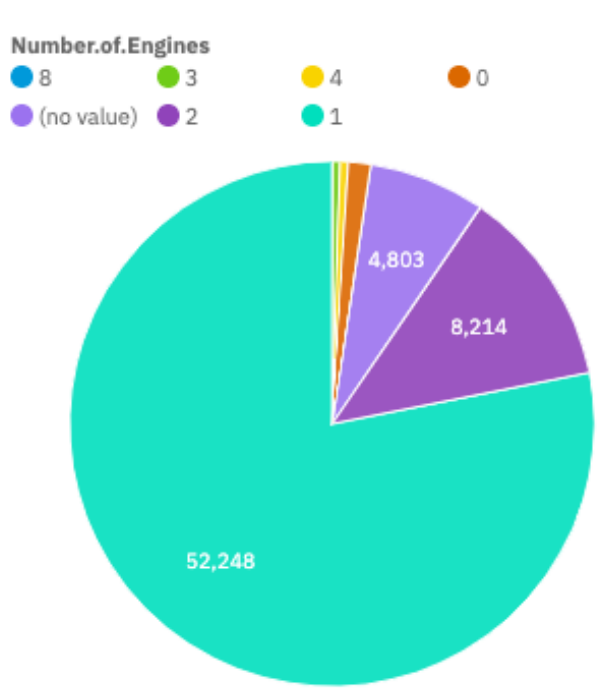

Figure 11: Number of Engines for Minor Aircraft Accidents

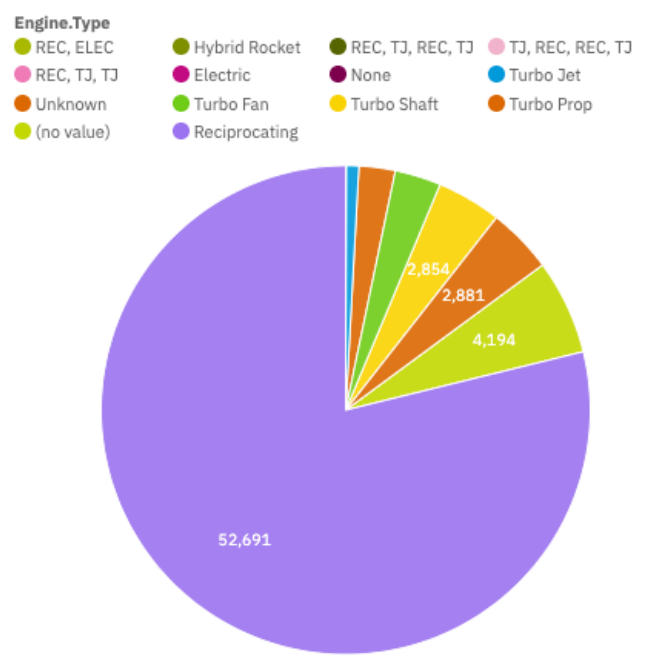

Figure 12: Engine Types for Minor Aircraft Accidents

\subsection{Engine Type}

Figure 12 shows that most aircrafts tend to have reciprocating engines. A reciprocating engine, also known as a piston engine, is one of the most common aircraft engine types.

*'no value' on the graph means that information was not available.

\subsection{Aircraft Damage and Injury Severity}

Figure 13 and Figure 14 show similar patterns: when aircraft damage is 'substantial', injury tends to be 'non-fatal'; when aircraft damage is 'destroyed', injury tends to be 'fatal'.

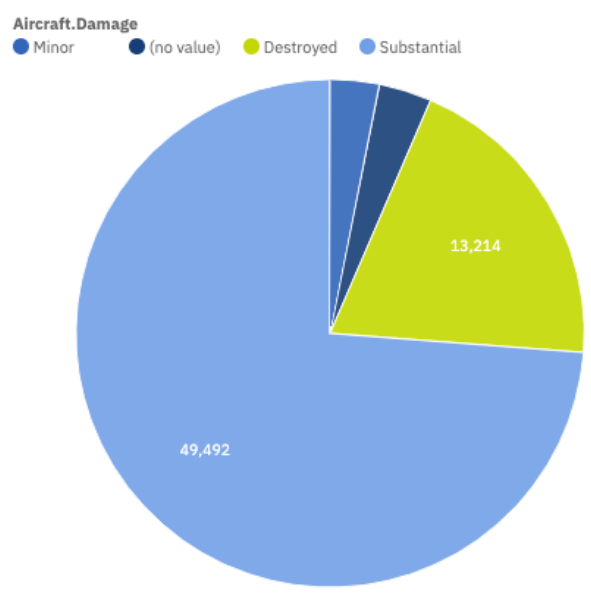

Figure 13: Aircraft Damage

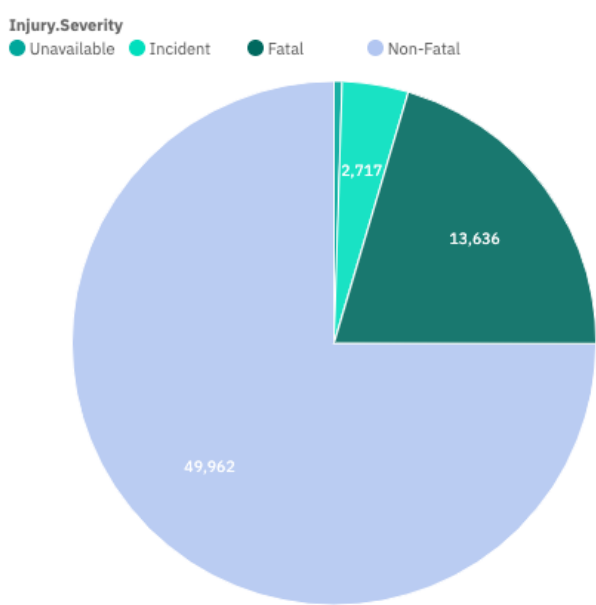

Figure 14: Injury Severity

*'no value' and 'Unavailable' on the graphs mean that information was not available.

\subsection{Purpose of Flight}

Figure 15 shows various purposes of flight for minor aircraft accidents. The most common purpose of flight is 'Personal'. Flight for instructional purposes is the second most common purpose of flight.

*'no value' on the graph means that information was not available.

\section{DISCUSSION}

\subsection{Limitations}

Although both datasets have a large amount of data, they have quite a number of unrecorded values, therefore some columns had to be either removed or filled with correct values. Also, while collecting 


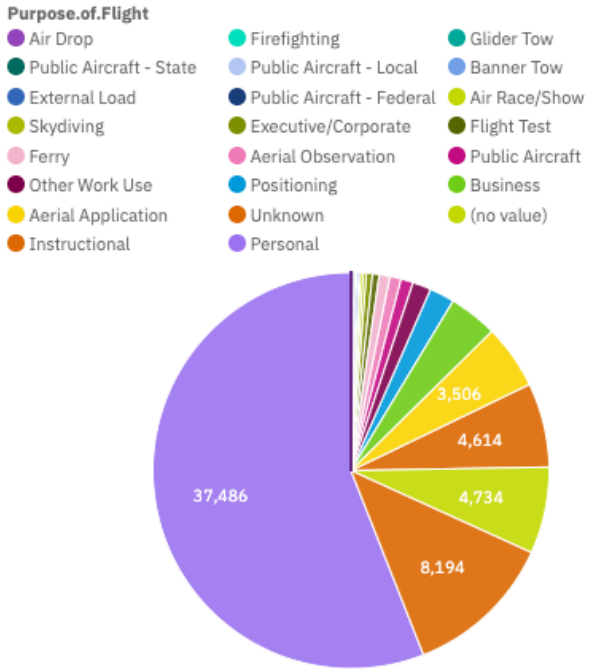

Figure 15: Purpose of Flight for Minor Aircraft Accidents

data on location names, there were many typographical errors, so they had to be replaced with correct spelling. In addition, working on two different datasets, comparing results and finding similarities/differences were the biggest challenges throughout the project. Similar findings helped to strengthen the validity of the analysis. However, since both datasets keep track of different records, some of the outcomes, such as location and date, were inconsistent which made it difficult to find correlations.

\subsection{Areas of Improvement}

One important area of improvement is finding correct values for blank cells. Due to the lack of records, some interesting columns that could have potentially expanded the findings had to be removed. Another way to improve the study would be to collect more strongly correlated variables. Although both datasets had quite a number of variables, many variables did not have strong correlations. By collecting more and better data, this topic can be examined more thoroughly.

\subsection{Next Steps}

One solution that could help reduce the number of crashes is technological advancement. For example, the development and implementation of Automatic Dependent Surveillance-Broadcast (ADSB) technology will help reduce the risk of airplane collisions and weather-related accidents, provide more efficient routes under adverse weather conditions, and improve situational awareness for pilots [3]. Advancement in technology will be the first step in preventing any further flight accidents.

\section{CONCLUSION}

By using IBM's Watson Analytics and Cognos Analytics and comparing two different datasets, this research has discovered some compelling patterns for airplane crashes. The most prominent finding is that crashes and fatalities have decreased while the number of passengers has increased. Furthermore, patterns on each different variable, such as location, operator, and phase of flight, provide us with deeper insights into the airplane crash patterns.

The main objective of this project is to raise awareness of flight safety and better understand its problems and progress, so that aviation industries can continue to improve. We hope that more information and understanding will lead to industry changes that save lives.

\section{REFERENCES}

[1] Cem. Airplane Crash Data Since 1908. Kaggle, Kaggle, 20 Aug. 2019, www.kaggle.com/cgurkan/airplane-crash-data-since-1908.

[2] Cho, SeongJoon, and Randy Olson. 2017. As Billions More Fly, Here's How Aviation Could Evolve. Air Travel Projected to Double Over Next 20 Years, National Geographic, 22 June 2017, www.nationalgeographic.com/environment/urbanexpeditions/transportation/air-travel-fuel-emissions-environment/.

[3] Federal Regulatory Directory: the Essential Guide to the History, Organization and Impact of U.S. Federal Regulation. CQ Press, 2014.

[4] Gershman, Mikhail, et al. 2018. Open Innovation in Russian State-Owned Enterprises. Industry and Innovation, vol. 26, no. 2, 2018, pp. 199-217., doi:10.1080/13662716.2018.1496815.

[5] Grandi, Sauro. 2016. Airplane Crashes Since 1908. Kaggle, Kaggle, 9 Sept. 2016, www.kaggle.com/saurograndi/airplane-crashes-since-1908.

[6] McCarthy, Niall. 2017 Was The Safest Year In The History Of Commercial Air Travel [Infographic]. Forbes, Forbes Magazine, 2 Jan. 2018, www.forbes.com/sites/niallmccarthy/2018/01/02/2017-was-the-safest-year-inthe-history-of-commercial-air-travel-infographic/\#7dae662960d4.

[7] Morris, Hugh. 2018. Do Russian Airlines Still Have a Safety Problem? The Telegraph, Telegraph Media Group, 12 Feb. 2018, www.telegraph.co.uk/travel/traveltruths/are-russia-airlines-safe/.

[8] Reim, Garrett. 2020. Iran Admits Shooting down Ukrainian 737 by Accident. Flight Global, FlightGlobal, 11 Jan. 2020, www.flightglobal.com/safety/iran-admitsshooting-down-ukrainian-737-by-accident/136104.article.

[9] Samaha, Kheirallah. 2020. Aviation Accident Database \& Synopses. Kaggle, Kaggle, 15 Jan. 2020, www.kaggle.com/khsamaha/aviation-accident-database-synopses.

[10] Spruit, M. 2016. From Airplane Crash to Stock Price Crash: The Effect of Airplane Crashes on the Stock Market. Erasmus University Thesis Repository, 29 July 2016, thesis.eur.nl/pub/35491/.

[11] Williams, Ashley. Exploring the Weather Hazards behind 5 Deadly, Notorious Plane Crashes. Local Weather from AccuWeather.com - Superior Accuracy ${ }^{T M}$, AccuWeather, www.accuweather.com/en/weather-news/exploring-the-weatherhazards-behind-5-deadly-notorious-plane-crashes/360542. 